\title{
Parental Oxytocin and Early Caregiving Jointly Shape Children's Oxytocin Response and Social Reciprocity
}

\author{
Ruth Feldman*,', Ilanit Gordon², Moran Influs', Tamar Gutbir' and Richard P Ebstein ${ }^{3}$ \\ 'Department of Psychology and the Gonda Brain Sciences Center, Bar-llan University, Ramat Gan, Israel; ${ }^{2}$ The Child Study Center, Yale University, \\ New Haven, CT, USA; ${ }^{3}$ Department of Psychology, National University of Singapore, Singapore, Singapore
}

\begin{abstract}
Oxytocin (OT) has an important role in bond formation and social reciprocity, and animal studies indicate that OT functioning is transferred from parent to child through patterns of parental care. Perspectives on attachment suggest that the individual's various attachment bonds are underpinned by the oxytocinergic system. However, prospective human studies that demonstrate the crossgeneration transfer of OT as mediated by early caregiving and its impact on children's multiple attachments are lacking. To address these concerns, the current study included 160 mothers and fathers and their firstborn child who participated in a 3-year longitudinal study. At the first and sixth postpartum months, parents' plasma OT was assayed, parent-infant interactions were videotaped and micro-coded, and allelic variations on the OXTR(rs2254298, rs 1042778) and CD38rs3796863 genes were measured. At 3 years, parents' and child's salivary OT was assessed and children's social reciprocity observed during interactions with mother, father, and their first best friend. Parents' OT levels were individually stable across the 3-year period, correlated with low-risk OXTR and CD38 alleles, and predicted child OT. Child's social reciprocity with friend was associated with child OT levels, mother's OT-related genes and hormones, and motherchild reciprocity, but not with father's genes, hormones, or behavior. A cross-generation gene-by-environment effect emerged, with low child OT levels predicted by the interaction of maternal high-risk CD38 allele and diminished maternal care in infancy. These results demonstrate individual stability in peripheral OT across several years and describe a cross-generation transfer of OT through caregiving in humans within a prospective longitudinal design. Consistent with other mammals, biobehavioral experiences within the parent-infant bond shape children's affiliative biology and social behavior across multiple attachments. Our findings bear important implications for conditions involving disruptions to maternal-infant bonding and underscore the potential for peer-based interventions.

Neuropsychopharmacology (20 I3) 38, I I54-I I62; doi: I0.1038/npp.20 I3.22; published online I3 February 2013
\end{abstract}

Keywords: oxytocin; CD38; maternal behavior; fathering; bonding; friendship

\section{INTRODUCTION}

Since the work of the early ethologists (Lorenz, 1950; Tinbergen, 1963) and Bowlby's (1958, 1969) seminal formulations on attachment, the parent-infant bond was thought to provide the foundation for the infant's capacity to enter the social world, form bonds with nonkin, and eventually nurture the next generation. Following these perspectives, animal studies have shown that biobehavioral provisions embedded in the mother-infant bond organize the infant's physiological systems, stress response, and social orientation (Denenberg and Rosenberg, 1967; Hofer, 1995). More recently, research has underscored the role of oxytocin (OT) - a nine-amino-acid neuropeptide synthesized in the hypothalamus - as providing the neurohormonal substrate for mammalian social bonding, and indicated

*Correspondence: Dr Ruth Feldman, Department of Psychology and the Gonda Brain Sciences Center, Bar-llan University, The Leslie and Susan Gonda Brain Science Center, Ramat Gan 52900, Israel. Tel: 972353 I 7943, Fax: 9723535 0267,

E-mail: feldman@mail.biu.ac.il

Received II October 2012; revised 19 December 2012; accepted 28 December 2012; accepted article preview online 16 January 2013 that the neurochemical organization of OT is shaped in early life through patterns of maternal care, such as lickingand-grooming (Kappeler and Meaney, 2010). This extragenomic cross-generation transfer defines a biobehavioral feedback loop through, which maternal OT determines her caregiving behavior, which, in turn, organizes the infant oxytocinergic system through patterns of parental behavior (Champagne, 2008). However, due to obvious constrains on measuring OT in the brain or conducting cross-fostering studies in humans, and notwithstanding the large betweenspecies differences in OT neuroanatomy (Ross and Young, 2009), lacking are prospective longitudinal studies. Such studies offer the opportunity to directly demonstrate the cross-generation transfer of OT in humans that encompass the effects of early caregiving on the infant's future OT response and show the impact of the OT biobehavioral feedback loop on other attachments beyond the parentinfant bond.

Perspectives on attachment suggest that the three prototypes of bonding in mammals: parental, pair, and filial-which in humans describes attachment to close friends-share underlying biobehavioral mechanisms and are underpinned by the oxytocinergic system (Carter et al, 
2005; Feldman, 2012a). Human studies showed associations between peripheral levels of OT and genetic single nucleotide polymorphism (SNP) variability of the OT receptor gene (OXTR) with sensitive parenting (Bakermans-Kranenburg and van Ijzendoorn, 2008; Feldman et al, 2012; Gordon et al, 2010) and intranasal administration of OT enhanced parenting behavior (Weisman et al, (2012a)). Additionally, plasma OT levels increased during periods of romantic bond formation (Schneiderman et al, 2012), and OT administration improved couple interaction (Ditzen et al, 2009). Of note is that in both parental and romantic attachment higher peripheral OT correlated with greater social reciprocity between partners. Adults reporting better parental care in childhood showed higher peripheral OT, more sensitive parenting, and greater activations in OT-rich brain areas, highlighting the involvement of $\mathrm{OT}$ in the cross-generational transfer of attachment (Feldman et al, 2012; Strathearn et al, 2009). Yet, empirical evidence for this transfer is retrospective and draws on adults' memories of parental care. Prospective studies that can detail the joint contribution of parental OT and early caregiving to children's OT response and social reciprocity are thus important for both better understanding of human attachment and the formation of specific interventions for conditions involving disruptions to maternal-infant bonding, including postpartum depression, premature birth, or contextual risk.

Close friendships serve as an important link between early attachment to parents and later attachment to nonkin that culminates in pair-bonding. Availability of close friends is associated with mental health (Gayer-Anderson and Morgan, 2012), physical well-being (Seeman, 1996), and life satisfaction (Ellison, 1990). Between the age of 3 and 4 years, children begin to form selective and enduring bonds with their first 'best friend", following a period of parallel-play and ubiquitous friendships in toddlerhood (Eckerman et al, 1989; Howes, 1988). Preschoolers' social competence with peers is an index of emotional well-being and correlates with attachment to parents (Fagot, 1997), self-regulation (Ramani et al, 2010), low aggression (Rubin and Ross, 1982), and parent-child reciprocity across the first years of life (Feldman and Masalha, 2010).

Gene-by-environment interactions provide the theoretical framework for much current psychiatric research by suggesting that plasticity alleles identified for a number of genes alter the individual's sensitivity to environmental signals, leading at times to negative outcomes (Rutter et al, 2007), but as often to positive ones (Belsky et al, 2009). Although, little research examined gene-by-environment effects in the oxytocinergic neuropathway, few studies described the interplay of OT and contextual factors, for instance, OXTR SNP variations interacted with personal distress in predicting support-seeking behavior (Kim et al, 2010). In addition to OXTR, emerging human studies have followed animal models by showing that CD38, an ectoenzyme that mediates the release of OT from hypothalamic neurons through the mobilization of calcium, has an important role in human attachment (Higashida et al, 2012). In the context of parenting, it has been recently shown that parents carrying the low-risk A allele on the CD38rs3796863 gene who reported warm parental care in childhood showed more sensitive parenting to their infants (Feldman et al, 2012). Similar to the findings for CD38 knockout mice (Jin et al, 2007), lower plasma OT coupled with high-risk allele on the CD38 and OXTR genes predicted less sensitive parenting, illustrating the links between neurogenetic and peripheral markers with implications for understanding the biology of parenting.

The overall goal of this prospective longitudinal study was to examine the cross-generation transfer of human attachment by integrating neurogenetic and hormonal measures with ethologically-based observations of social behavior in multiple attachments over time. We measured plasma OT, SNP variations on the OXTR and CD38 genes, and parenting behavior in postpartum mothers and fathers at the first and sixth months after the birth of their first child. When children were 3 years old, parents' and child's salivary OT was measured and children's social reciprocity was assessed during interactions with mother, father, and their first 'best friend'. We selected SNPs on the OXTR and CD38 genes that have been linked with increased risk for disorders involving severe social dysfunction, including autism and major depression (Costa et al, 2009; Lerer et al, 2008, 2010, Riebold et al, 2011). Three hypotheses were proposed. First, we expected that parents' peripheral OT levels and reciprocal parenting style would be individually stable over time and correlate with more optimal allelic variations on OXTR and $C D 38$ genes. Second, the stable parental style and OT measures were expected to each predict the child's OT response and reciprocal social behavior toward parents and friends. Third, given its role in the cross-generation transfer of human parenting, a geneby-environment interaction was expected, so that more optimal allelic variations on the parents' $C D 38$ gene would interact with early parenting to shape children's OT response. By using a prospective longitudinal design and implementing a multidisciplinary approach, including behavioral observations, biomarkers, and SNPs, we hoped to shed further light on the neurobiological mechanisms underlying human attachment.

\section{MATERIALS AND METHODS}

\section{Participants}

One-hundred-and-sixty cohabitating parents (80 couples) and their firstborn infant participated when infants were 1 months old. Of these, 128 parents (66 mothers, 62 fathers) were seen again at 6 months $(\mathrm{M}=24.8$ weeks, $\mathrm{SD}=4.38)$, and 98 parents (50 mothers, 48 fathers) were revisited when children were three years $(M=38.9$ months, $S D=2.68)$. The 3 -year visit also included 50 'best friends' of a similar age to the target child, who was invited to the family home in advance to participate in a study on friendships. At study initiation, fathers' age averaged $29.45(\mathrm{SD}=3.87)$ and education 15.7 years $(\mathrm{SD}=2.85)$ and mothers' age averaged $27.24(\mathrm{SD}=3.67)$ and education $16.08(\mathrm{SD}=2.22)$ years. Parents were middle class, completed at least high-school education, and the infant was the first to both parents. All parents were Caucasians. Infants (37 boys) were healthy singletons and showed typical development. The research was approved by the Institutional Review Board, was 
conducted according to ethical standards, and all participants (including friend's parents) signed an informed consent.

\section{Procedure}

To observe social interactions in their natural habitat, all assessments in the infancy and preschool stages were conducted at the family home during the afternoon hours (0400-0800 hours, to control for diurnal variability in OT). In the two infancy visits, blood was first drawn from each parent for OT assessments and at the first visit parents also provided DNA for genotyping. Following, each parent was videotaped interacting freely with the child in counterbalanced order. Instructions were 'play with your infant as you typically do'. OT collection was set to a time between feeding and was not conducted within the half-hour before or after breastfeeding. At 3 years, salivary OT was collected at baseline and after social interactions from parents and child. After baseline saliva collection, each parent interacted with the child for 7 minutes using age appropriate toys selected on the basis of research on child play (Feldman, 2007). Following, a 10-min interaction between the child and best friend was videotaped during structured play with a toy that included animal farm and props. A second salivary sample was collected from parents and child 10 minutes after play.

We chose to collect salivary, rather than plasma OT at this stage, as ethical concerns precluded drawing blood from young children without medical reasons. Although salivary and plasma OT may tap somewhat different biological processes, studies have shown medium-level correlations between the two (Feldman et al, 2010, 2011), and intranasal OT administration was found to increase both plasma (Burri et al, 2008) and salivary OT (Weisman et al, 2012b). Saliva is also more easily collected at multiple time-points for test-retest reliability. To assess the relations of parents' and child's OT from the same fraction, we measured salivary OT from both parents and child at 3 years.

\section{OT collection and analysis}

Plasma. At infancy visits, parents' blood was drawn from antecubital vein into $9 \mathrm{ml}$ chilled vacutainer tubes containing lithium heparin that were supplemented with $400 \mathrm{KIU}$ of Trasylol (Bayer, Leverkusen, Germany) per $1 \mathrm{ml}$ blood. OT samples were kept ice-chilled for up to $2 \mathrm{~h}$ before being centrifuged at $4{ }^{\circ} \mathrm{C}$ at $1000 \mathrm{~g}$ for $15 \mathrm{~min}$. Supernatants were collected and stored at $70^{\circ} \mathrm{C}$ until assayed. Parents were asked to refrain from food intake $30 \mathrm{~min}$ before blood draw. Blood was drawn at least $30 \mathrm{~min}$ after and $30 \mathrm{~min}$ before nursing.

Saliva. OT at 3 years was collected by Sallivettes (Sarstedt, Rommelsdorft, Germany). Parents were asked to chew a roll of cotton for $40 \mathrm{~s}$ and put a similar roll in their child's mouth. Salivettes were kept ice-chilled for up to $1 \mathrm{~h}$ before centrifuged at $4{ }^{\circ} \mathrm{C}$ at $1500 \mathrm{~g}$ for $15 \mathrm{~min}$. The liquid samples were stored at $-80^{\circ} \mathrm{C}$. To concentrate the samples by 3 or 4 times, the liquid samples were lyophilized overnight and kept in $-20^{\circ} \mathrm{C}$ until assayed. The dry samples were reconstructed in the assay buffer immediately before analysis, consistent with previous research (Feldman et al, 2007). Plasma and salivary
OT levels measured simultaneously have shown to be interrelated (Feldman et al, 2010).

Determination of OT was performed by commercial OT enzyme-linked immunosorbent assay kit (Assay Design, Ann Arbor, Michigan) as described previously (Carter, 2007; Feldman et al, 2007, 2010). Measurements were performed in duplicate and concentrations of samples were calculated by using MATLAB-7 (The MathWorks, Inc. Natick, MA) according to relevant standard curves. The intra-assay and inter-assay coefficients were less than 7 and $15.8 \%$, respectively.

\section{Genetyping collection and analysis:}

Genotyping. DNA was extracted from $20 \mathrm{ml}$ of mouthwash samples using Master Pure kit (Epicenter, Madison, WI). Genotyping of OXTR SNPs was performed using the SNaPshot Method (Applied BioSystems, Foster City, CA, USA) as previously described (Lerer et al, 2008). Amplification of the OXTR was done using these primers;

Primers used in genotyping the OXTR SNPs:

\begin{tabular}{|c|c|c|}
\hline SNP & Ist $P C R$ primers & 2nd PCR primer extensions \\
\hline $\begin{array}{l}\text { OXTR } \\
\text { rs I } 042778\end{array}$ & $\begin{array}{c}\text { F: 5'-TGGGTTCAGGGTGGTAG } \\
\text { AAG' } 3 \text {, R: 5'- } \\
\text { AGGCTGTGCTGGCATA } \\
\text { AGTG-' } 3 .\end{array}$ & $\begin{array}{l}(\mathrm{T}){ }_{12} 5^{\prime}- \\
\text { TGAAGCCACCCCAAG } \\
\text { GAG }{ }^{\prime} 3\end{array}$ \\
\hline $\begin{array}{l}\text { OXTR } \\
\text { rs } 2254298\end{array}$ & $\begin{array}{c}\text { F: 5'-CCCAGAGGTCTGTGGG } \\
\text { TGTA-'3, R: 5'- } \\
\text { GTCAGGGAGGAGCTGTT } \\
\text { CTG-'3 }\end{array}$ & $\begin{array}{c}(\mathrm{T}) 6^{\prime}- \\
\text { AAGAAGCCCCGCAA } \\
\text { ACTG' } 3\end{array}$ \\
\hline
\end{tabular}

The CD38 SNP rs3796863 (A/G) was genotyped using high-resolution melt (HRM) analysis. PCR reactions were performed using $5 \mu \mathrm{l}$ Thermo-Start Master Mix (Thermo scientific), $2 \mu \mathrm{l}$ primers $(2.5 \mu \mathrm{M}), 1 \mu \mathrm{l}$ SYTO9 (dye), and $1 \mu \mathrm{l}$ of water to total of $9 \mu \mathrm{l}$ volume and an additional $1 \mu \mathrm{l}$ of genomic DNA. All PCR reactions and HRM analysis were performed on a Rotor-Gene 3000 (Corbett life science, Australia), using the following primers that produced a 162 bp amplicon: F: 5'-GGTGCACAGACCACTTAGCA-3'; R: 5'-TCGGAAGAGAGGAAAGCAAA- $3^{\prime}$. PCR reaction conditions were as follows: activating enzyme step at $95.0^{\circ} \mathrm{C}$ for $15 \mathrm{~min}, 45$ cycles of denaturation at $95.0^{\circ} \mathrm{C}$ for $5 \mathrm{~s}$, reannealing at $60^{\circ} \mathrm{C}$ for $15 \mathrm{~s}$ and extension at $72{ }^{\circ} \mathrm{C}$ for $10 \mathrm{~s}$. The reaction proceeded to a hold at $40^{\circ} \mathrm{C}$ for $2 \mathrm{~min}$, a second hold at $82{ }^{\circ} \mathrm{C}$ for $2 \mathrm{~min}$ and then the melt procedure ramped from $82-90{ }^{\circ} \mathrm{C}$ raising by $0.1{ }^{\circ} \mathrm{C}$ every $3 \mathrm{~s}$ where fluorescence was acquired. HRM distinguished between the three genotypes (AA, AG, and GG) and the method was verified by comparison of a portion of HRM results to those obtained by genotyping the same samples using the SNaPShot procedure (Applied Biosystems) described above. All genotype frequencies of OXTR and CD38 SNPs were in Hardy-Weinberg equilibrium. The CC allele on CD38 rs3796863 has been linked with greater risk for autism in two independent studies (Lerer et al, 2010; Munesue et al, 2010), and the GG allele on the OXTR rs2254298 is related to greater risk for autism (Lerer et al, 2008-check in brune) and depression (Costa et al, 2009). The TT allele on the OXTR(rs1042778) correlates with greater risk for autism 
(Lerer et al, 2010) and lower empathy in healthy adults (Wu et al, 2012). These SNPs were thus defined as 'risk alleles'. Several studies provide evidence for functionality for these SNPs. All three risk alleles have been linked with lower plasma OT in Caucasian adults (Feldman et al, 2012); the GG allele on the OXTR rs2254298 has been associated with smaller amygdala volume in two studies (Furman and Chen 2011; Inoue et al, 2010); and evidence points to the involvement of CD38 rs3796863 in transcription (Lerer et al, 2010). Distributions of alleles in the current sample were as follows: women: CD38rs3796863: AA,AC/ $\mathrm{CC}=48 / 32$, OXTR $(\mathrm{rs} 2254298) \quad \mathrm{AA}, \mathrm{AG} / \mathrm{GG}=47 / 33$, OXTR $(\mathrm{rs} 1042778) \quad \mathrm{GG}, \mathrm{GT} / \mathrm{TT}=52 / 28$; men: $\mathrm{AA}, \mathrm{AC} / \mathrm{CC}=46 / 34$, $\operatorname{OXTR}(\mathrm{rs} 2254298) \quad \mathrm{AA}, \mathrm{AG} / \mathrm{GG}=48 / 32, \quad O X T R(\mathrm{rs} 1042778)$ $\mathrm{GG}, \mathrm{GT} / \mathrm{TT}=53 / 27$.

\section{Behavior coding}

Infancy. Interactions were micro-coded by trained coders on a computerized system (Noldus, Wageningen, Netherlands), consistent with previous research (Feldman and Eidelman, 2004). At 1 month, four categories of parenting behavior were coded: Gaze-to infant, object, and gaze aversion. Affect-positive, neutral, and negative. Vocalizations: 'motherese' (high-pitched rhythmic vocalizations), adult-speech, and none. Touch-affectionate, functional, stimulatory, and none. Proportions of gaze to infant, positive affect, 'motherese' vocalizations, and affectionate touch were summed into a parent care composite. Similar codes were applied at 6 months, and the proportion of time parent spent in positive affect, 'motherese' vocalizations, or affective touch given infant showed social gaze and positive vocalizations was summed. Consistent with prior research (Feldman and Eidelman, 2007), an Early Parental Care composite was computed as the average of the parental care composites at 1 and 6 months. This composite describes the proportion of time out of the entire session the parent engaged in the typical parenting behaviors. Inter-rater reliability for $20 \%$ of the interactions averaged $98 \%(\mathrm{kappa}=0.84)$.

At 3 years, sessions with parents and friends were coded with the Coding Interactive Behavior manual (CIB, (Feldman, 1998). The CIB is a global rating system for social interactions that includes 45 codes rated from 1-5, which are aggregated into several composites with good psychometric properties (Feldman, 2012b). The Social Reciprocity construct was used, and this CIB composite has shown stability across six observations from infancy to adolescence and good internal consistency (Feldman, 2010). Social Reciprocity defines interactions where the two partners are moving in harmony, each contributes to the mutual dialog, and exchanges are the end product of inputs from both partners. Reciprocity was the average of following codes: partners engage in give-andreceive interactions that are sensitive to verbal and nonverbal cues, adapt to each other's needs, communications, and requests; engaged in shared activity; and interaction is fluent and rhythmic (alpha levels for internal consistency of the Social Recirpocity Construct were $0.92,0.88,0.86$ for mother, father, and friend, respectively).

\section{STATISTICAL ANALYSIS}

Differences between mothers and fathers in hormones and behavior, and differences related to genetic variability were
Table I Mothers', Fathers', and Children's OT and Social Behavior

Means (SD) Minimum Maximum N

\begin{tabular}{llrrr}
\hline Newborn period & & & & \\
Mother plasma OT $(\mathrm{pg} / \mathrm{ml})$ & $337.35(195.64)$ & 147.8 & 1351.0 & 76 \\
Father plasma OT $(\mathrm{pg} / \mathrm{ml})$ & $401.98(360.28)$ & 51.4 & 2752.3 & 76
\end{tabular}

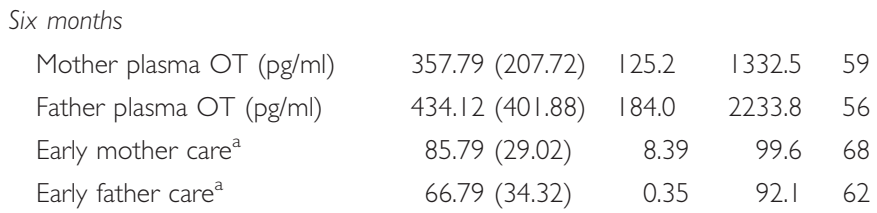

\begin{tabular}{|c|c|c|c|c|}
\hline \multicolumn{5}{|l|}{ Three years } \\
\hline $\begin{array}{l}\text { Mother salivary OT (pg/ml)- } \\
\text { baseline }\end{array}$ & $7.86(3.8 I)$ & 0.38 & 19.69 & 49 \\
\hline Father salivary OT-baseline & I $1.00(6.28)$ & 2.74 & 34.24 & 46 \\
\hline Child salivary OT-baseline & $7.18(6.17)$ & 1.25 & 33.40 & 48 \\
\hline $\begin{array}{l}\text { Mother salivary OT (pg/ml)- } \\
\text { postplay }\end{array}$ & $7.91(4.7)$ & 0.93 & 22.23 & 49 \\
\hline Father salivary OT-postplay & $9.92(5.09)$ & 0.93 & 27.05 & 46 \\
\hline Child salivary OT-postplay & $6.25(3.84)$ & 0.38 & 21.38 & 48 \\
\hline Mother-child reciprocity ${ }^{b}$ & $4.15(.82)$ & 2.00 & 5.00 & 50 \\
\hline Father-child reciprocity ${ }^{b}$ & $3.97(.99)$ & 1.33 & 5.00 & 48 \\
\hline Child-friend reciprocity ${ }^{b}$ & $3.68(1.10)$ & 1.50 & 5.00 & 50 \\
\hline
\end{tabular}

a number represent percentage of time parent provided parenting behavior averaged from the first-and sixth-month observations.

bumbers represent codes on a scales of $\mathrm{I}-5$.

tested with ANOVA. Pearson correlations examined individual stability in hormones and behavior, and longitudinal and concurrent relations between parent-child and child-friend reciprocity. Hierarchical regressions were used to predict (a) child-friend reciprocity from parental OT, child OT, early parental care, and concurrent parentchild reciprocity; and (b) gene-by-environment effects on Child OT from parents' CD38, early parenting, and their interaction.

\section{RESULTS}

\section{Stability in Parents' OT and Behavior and Links with Genetic Variability}

Descriptive statistics for parents' and child's hormones and behavior are presented in Table 1. OT distribution was clustered around the center with a long right tail (Kurtosis: 28.17, $\mathrm{SE}=0.17$; Skewness: $4.32, \mathrm{SE}=0.88$ ), and was fit by KAPPA, BURR, and log-logistic distributions. Once outliers $>3$ SD above the mean $(>1000 \mathrm{pM})$ were excluded $(\mathrm{N}=2$; 1 mother, 1 father), parameters improved substantially (Kurtosis: 1.77, SE:0.16, skewness:1.22, SE; 0.86) and the distribution was log-normal. OT values were log-transformed before statistical analyses. Plasma OT was unrelated to demographic variables, including age, education, height, weight, smoking, time since last meal, menstrual cycle phase, contraceptive intake, and among mothers to mode of delivery (vaginal vs c-section), and weeks since birth. 

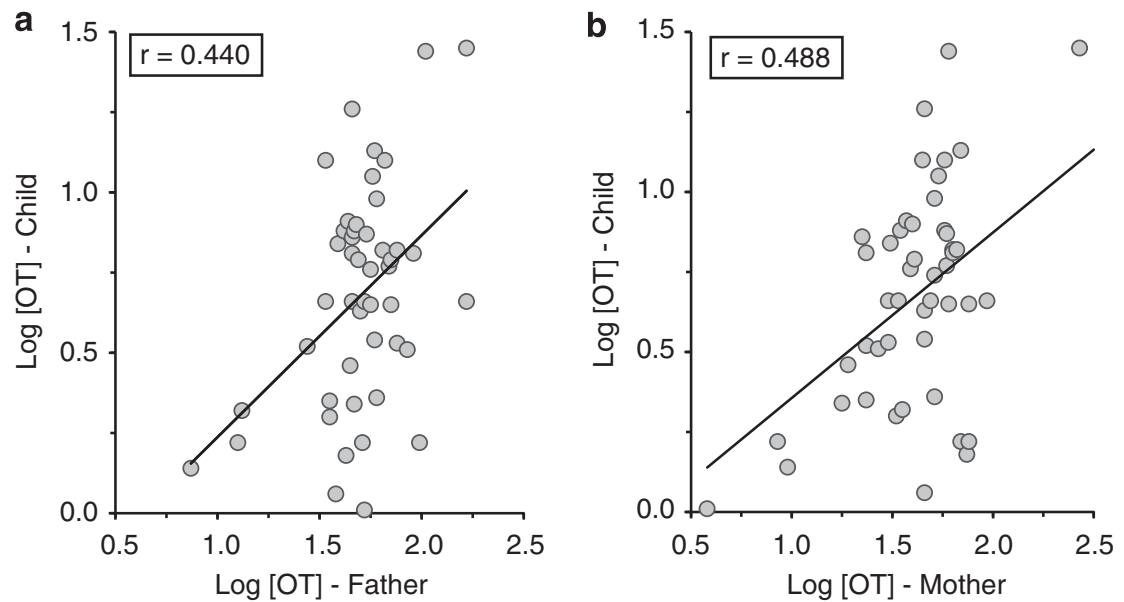

Figure I Correlations between child salivary oxytocin at 3 years with mother's (a) and father's (b) oxytocin across the first 3 years of parenthood.

Eighty-seven percent of mothers were breastfeeding at first assessment and $58 \%$ were still breastfeeding by 6 months. Consistent with previous research (Feldman et al, 2007; 2010), no differences were found between breastfeeding and nonbreastfeeding mothers when OT was not sampled within the time surrounding breastfeeding.

Maternal and paternal plasma OT levels in the two infancy assessments showed high individual stability, $r_{\text {mother }}=0.91, \quad r_{\text {father }}=.88$ ps $<0.001$, and were averaged into a single score. Similarly, the two salivary samples before and after play were highly correlated in each parent, $r_{\text {mother }}=0.77, r_{\text {father }}=0.75, \mathrm{ps}<0.001$, and were averaged into a single score. The infancy and three-year OT scores were individually stable in both mothers, $r=0.50, p<0.001$, and fathers, $r=0.44, p<0.01$. The four assessments (log OT) at first month, 6 months, 3 years baseline, and 3 years post play were averaged into a Parent OT score, which represents the parent's stable OT across the first 3 years of parenting. Mothers' and fathers' Parent OT scores were interrelated, $r=0.41, p<0.01$. Log OT values were for mothers: $\quad M=0.59 \quad(S D=0.44), \quad$ fathers: $M=0.62$ $(\mathrm{SD}=0.48)$, and children: $\mathrm{M}=0.44(\mathrm{SD}=0.36)$.

Genes, hormones, and behavior. Mothers homozygous for the CC allele on CD38rs3796863, compared with A carriers, showed lower parent OT, $F(1,49)=4.96, p=0.029$, and reduced early parental care, $F(1,65)=3.86, \quad p=0.048$. Mothers homozygous for the TT allele on the OXTRrs1042778 also showed lower parent OT compared with $\mathrm{G}$ carriers, $F(1,49)=4.37, p=0.038$. Mothers homozygous for the GG allele on OXTR rs2254298 showed diminished early parental care, $F(1,65)=3.92, p=0.045$. Fathers homozygous for the CC allele on the CD38rs3796863 also showed lower peripheral OT, $F(1,47)=3.97, p<0.05$. Early parental care was associated with higher parent $\mathrm{OT}$, $r_{\text {mother }}=0.37, p<0.01, r_{\text {father }}=0.31, p<0.05$.

\section{Cross-Generation Transfer of Parental and Child's OT and Social Reciprocity}

Hormonal transfer. The baseline and postinteraction assessments of child salivary OT were correlated $(r=0.74$, $p<0.001)$ and averaged into child OT composite. As predicted, child OT correlated with maternal OT, $r=0.48$, $p<0.001$, and paternal OT, $r=0.44, p=0.002$, the stable parental OT across the first 3 years of parenting (Figure 1), and these correlations were unaffected by extreme values or the median split.

Behavioral transfer. Early maternal care was associated with mother-child reciprocity at 3 years, $r=0.33, p<0.05$. However, early paternal care was unrelated to father-child reciprocity at 3 years, $r=0.16, p>0.10$, indicating that mothering shows greater continuity from infancy onward compared with fathering. As expected, child OT correlated with greater social reciprocity with best friend, $r=0.37$, $p=0.018$.

Multiple attachments transfer-from parental to filial attachment. Children's social reciprocity with best friend was associated with mother-child reciprocity, $r=0.40$, $p<0.01$; however, father-child reciprocity was unrelated to child social reciprocity with best friend, $r=0.12, p>0.10$. Child-friend reciprocity was not directly related to early parental care with either mother or father, suggesting that the transfer from parental to filial attachment rides on the continuity in the maternal style and on the parents' effects on child OT. A regression model predicting child-friend reciprocity from parent OT, child OT, early parental care, and parent-child reciprocity (average of maternal and paternal care and reciprocity) was significant: $R^{2}$ total $=0.24, F(6,44)=4.87, p<0.01$. Independent predictors of child-friend Reciprocity were parental OT, $R^{2}$ change $=0.07$, $F(1,44)=4.31, \quad p=0.03$, child $\mathrm{OT}, \quad R^{2}$ change $=0.09$, $F(1,44)=4.68, \quad p=0.027$, and parent-child reciprocity, $R^{2}$ change $=0.05, F(1,44)=3.71, p=0.05$. No interaction terms proved significant in this model.

To integrate genetic and hormonal biomarkers and test their cumulative effect on child social behavior, a 'cumulative OT risk' score was computed. We first summed risk on the three SNPs of the OXTR and CD38 genes, resulting in a variable ranging from 0 to 3 for each parent. This cumulative genetic risk showed negative correlations with parent OT, $r_{\text {mother }}=-0.36, \quad p=0.018, \quad r_{\text {father }}=-0.33$, $p=0.036$, suggesting consistency between the individual's OT biomarkers at the genetic and hormonal levels. Mother and father genetic OT risk was interrelated, $r=0.36$, $p=0.038$. Next, the parent OT score was divided into high and low OT $($ low $=1$, high $=0)$ by using the median split and added to the genetic risk score to create a cumulative $\mathrm{OT}$ risk score (ranging from 0 to 4 ). This cumulative score 


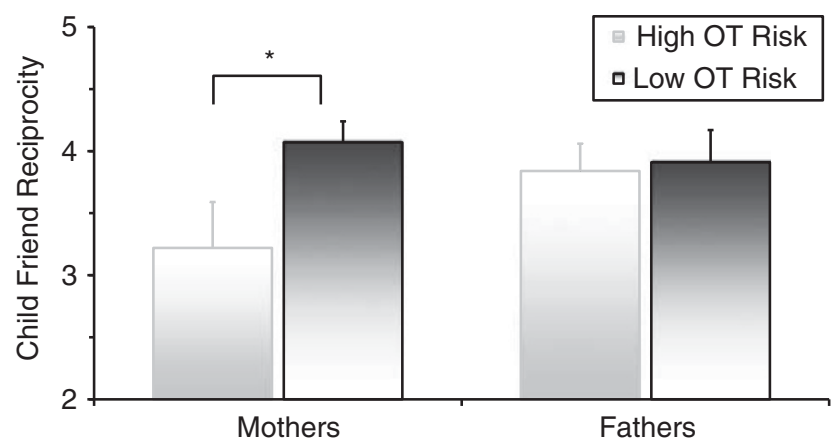

Figure 2 Child social reciprocity with best friend in relation to mother's and father's cumulative OT risk. The OT risk composite includes risk alleles on the OXTR and CD38 genes and low parental OT. * $p<0.05$.

was again split at the median to create high and low cumulative OT risk. Children whose mothers had low cumulative OT risk showed higher social reciprocity toward best friends compared with children of mothers with high cumulative OT risk, $F(1,49)=5.33, p=0.024$, but child social reciprocity with friend was unrelated to fathers' cumulative OT risk (Figure 2).

\section{Gene-by-Environment Effect on Children's OT Response}

Two hierarchical regression equations were computed predicting child's OT, stratified once from mother's and once from father's CD38 rs3796863, early parental care, and their interaction. Results indicate that the maternal model was significant, $\mathrm{R}^{2}$ total $=0.25, F(3,45)=5.77, p<0.01$, but not the paternal model. Independent predictors of child OT were maternal $C D 38$ rs3796863 A allele, $\mathrm{R}^{2}$ change $=0.08$, $F(1,44)=4.46, p=0.03$, and the interaction of $C D 38$ rs3796863 and early maternal care, $\mathrm{R}^{2}$ change $=0.13$, $F(1,44)=8.77, p<0.01$. To further examine the interaction, early maternal care was divided into high and low groups using the median split. Among children receiving low maternal care, those with mothers homozygous for the high-risk CC allele had lower OT levels $(M=3.96 \mathrm{pg} / \mathrm{ML}$, $\mathrm{SD}=2.41)$ than those whose mothers carried the A allele $(M=9.57 \mathrm{pg} / \mathrm{ML}, \mathrm{SD}=6.60), F(1,23)=4.86, p<0.05$. However, in the high-maternal-care group, children of mothers carrying the A allele showed comparable levels $(M=8.02 \mathrm{pg} / \mathrm{ML}, \mathrm{SD}=6.25)$ to children of mothers homozygous for the $\mathrm{C}$ allele $(M=6.73 \mathrm{pg} / \mathrm{ML}, \mathrm{SD}=4.92)$ (Figure 2$)$.

\section{DISCUSSION}

Attachment theory has long proposed that the human capacity to form affiliative bonds with nonkin social partners is shaped through biobehavioral experiences afforded by the mother-infant bond (Bowlby, 1969; Hofer, 1995). Although little prospective evidence supported this claim, much empirical and clinical work has been conducted within its framework. Results of the current study lend support to the attachment perspective in a prospective longitudinal design. We show that the infant's early caregiving experiences are partially shaped by peripheral and genetic markers on the parents' OT neuropathway and that parent OT and early parenting jointly support the child's social reciprocity in

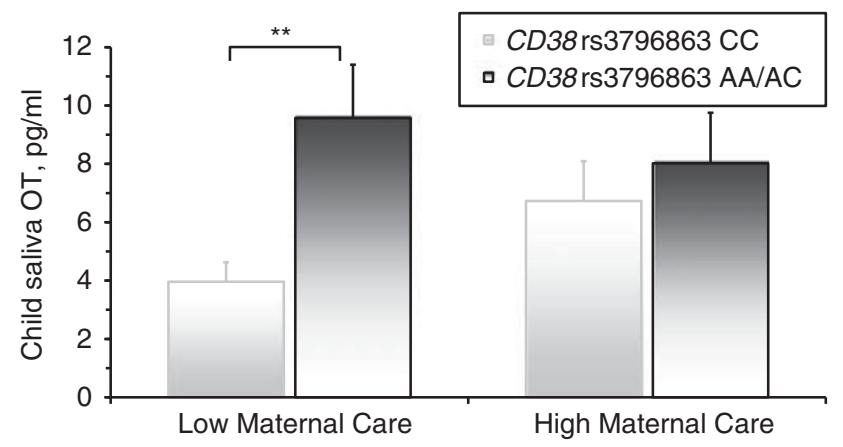

Figure 3 Child salivary OT at 3 years stratified by maternal CD38 gene and patterns of maternal care in Infancy. $* * * 0.02$.

multiple attachments. Furthermore, a cross-generation geneby-environment effect was found, with the mother's CD38 high-risk allele interacting with early caregiving in predicting the child's OT response, modeling a unique parental gene-byinfant-environment effect on child outcome. Overall, the findings underscore the CD38-OT-OXTR axis as a critical pathway in the cross-generation transfer of human attachment and social behavior (Brunetti and Malavasi, 2012) and highlight the mutual influences between affiliative biology and caregiving experiences as central in this transfer. An overall model of the findings is presented in Figure 4. The model describes the links between maternal and paternal genes and hormones, their associations with child OT, and the effects of child OT and mother-child, but not father-child reciprocity on children's social reciprocity with best friend.

Our results suggest that the cross-generation transfer of human attachment may relate to the mechanisms of individual stability following a period of neuroplasticity. Peripheral OT levels in plasma and saliva in mothers and fathers were found here to be individually stable across several years. Pervious research showed stability over several months (Feldman et al, 2007, Gordon et al, 2010). The currently reported long-term stability of peripheral OT suggests the notion that OT represents a 'trait-like' dimension of the individual that probably organizes in early infancy and can serve as an index of sociability, empathy, and affiliative tendencies, perhaps across the lifespan. Mothers', but not fathers' sensitive caregiving similarly showed stability over time. This is consistent with animal research indicating that maternal behavioral profiles are stable not only over time but across generations (Champagne, 2008) and human studies suggesting that fathering is less innate and develops in the context of mothering (Belsky, 1981). It is of interest that children's stable reciprocity with mother, not with father, predicted reciprocity with friend, although both maternal and paternal OT contributed to the development of child OT. Animal studies (Hofer, 1995; Kappeler and Meaney, 2010) indicate that adaptation to different qualities of maternal behavior during the period of neuroplasticity alters the brain's stress- and affiliation-related endocrine systems and forms the child's behavioral repertoire and social orientation. Similarly, although mother's cumulative OT risk, indexing the presence of risk alleles on the OXTR and CD38 genes and low parental OT, was related to diminished childfriend reciprocity, father's genes and hormones was not. 


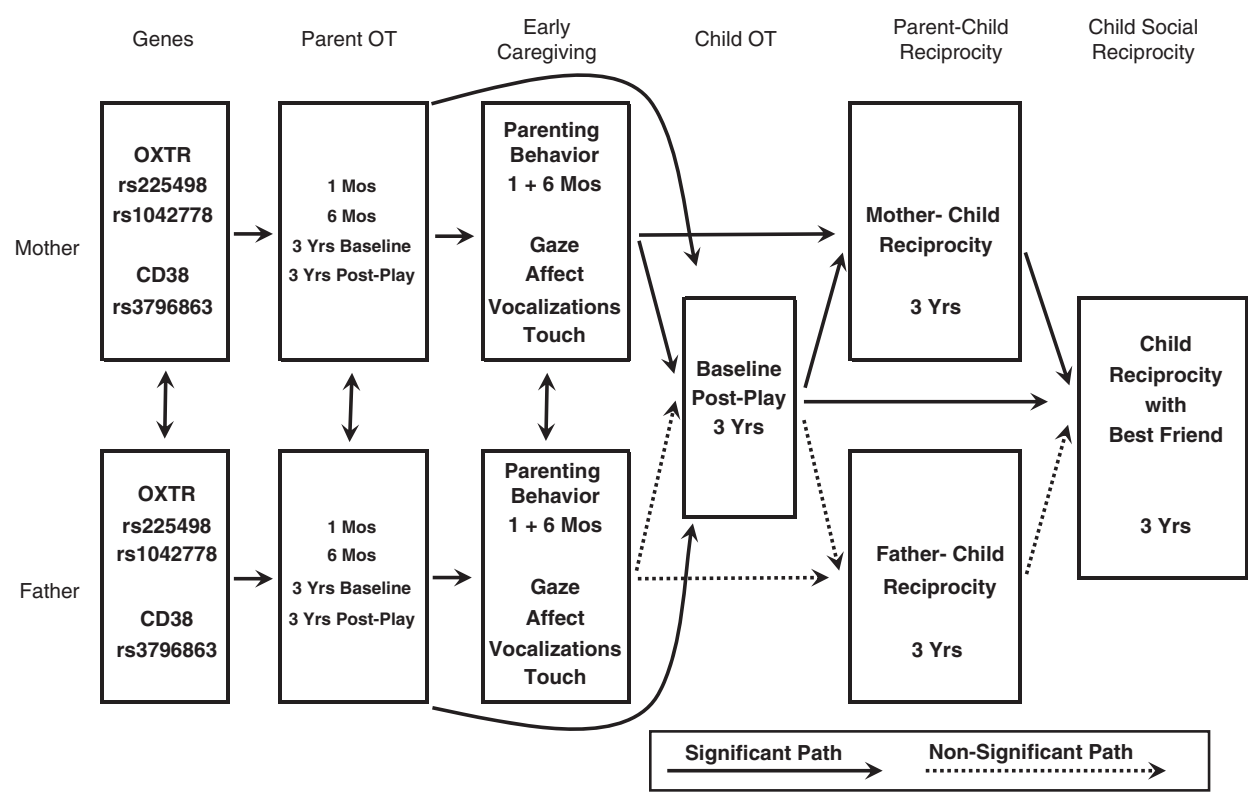

Figure 4 An overall model of the findings linking maternal and paternal genes, hormones and parenting behavior with child OT and social reciprocity.

Consistent with attachment theory, it appears that the mother's extended OT system provides the bridge from the parent-infant bond to the child's later attachments with nonkin. It is thus possible that maternal care and OT may function to shape both the father's caregiving behavior and the child's affiliative biology and social reciprocity, and this hypothesis is consistent with the primary physiological role of OT in birth and lactation. As such, the current findings highlight the first 6 months of parenting as a critical period for infant social adaptation and as focal point for intervention. During this early period-when infant affiliative biology consolidates through patterns of parental care-interventions that focus on enhancing parental care, increasing father involvement, and promoting maternal touch, which in turn releases maternal OT (Feldman et al, 2010), may have long-term positive effects on children's social growth.

The pathway leading from early parenting to child outcome partly originates in the parents' genetic makeup. As seen, the parent's cumulative genetic risk was related to lower peripheral OT across the first 3 years of parenting, particularly allelic variations on the maternal and paternal CD38 gene. Interest in CD38 and human social behavior was catalyzed by the findings that $\mathrm{CD} 38-/-$ mice are characterized by partial social amnesia that could be restored by OT administration, leading to the discovery that the CD38 ectoenzyme is required for the release of brain OT. CD38 is an ectoenzyme that cleaves $\mathrm{NAD}^{+}$and $\mathrm{NADP}^{+}$, generating cyclic ADP ribose, NAADP, and ADPR. CD38 may has an important role in the regulation of $\mathrm{NAD}^{+}$ levels as well as modulate the activity of sirtuins, NADdependent deacetylases implicated in ageing, cell protection, and energy metabolism in mammalian cells. These reaction products are essential for the regulation of intracellular $\mathrm{Ca}^{2+}$, the most ancient and universal cell signaling system. To our knowledge, this is the first report indicating a gene-by-environment interaction for the CD38 gene regarding social behavior. $C D 38$ is characterized by a
CpG island $\sim 900 \mathrm{bp}$ long, encompasses exon 1 and the $5^{\prime}$-end of intron 1 , and contains a binding site for the transcription factor Sp1, suggesting that methylation may intervene in the process of CD38 gene regulation. Future studies of this gene and its related behavior might fruitfully examine the role of differential methylation in gene expression as a result of parenting. Overall, the current findings add to the very few studies on the involvement of CD38 in human social behavior, perhaps through a cross talk between the CD and OT systems, which connects OTbased processes with a family of molecules of wide-range functionality (Brunetti and Malavasi, 2012).

Friendships are central, albeit under-researched, component of the individual's well-being and social adaptation. As social creatures, humans need close friendships not only for survival but also for health, longevity, and life satisfaction, and a host of psychiatric conditions are associated with the inability to form and maintain close ties with others (Baumeister and Leary, 1995; Cohen, 2004). Harlow and Suomi (1971) noted that peers can serve as 'therapists' when parenting is deficient, particularly at the transition from infancy to childhood. When 6-month-old isolated monkeys where introduced to 3-month-old normal peers, the exchange reversed much of the effects of maternal deprivation on social behavior, unlike the findings for adult surrogates. At around 3 years, children begin to form friendships with age mates, which require different types of reciprocity from those experienced with parents but, which similarly activate their affiliatve biology. In forming their first nonkin attachments, children draw not only on mechanisms of social learning from parents, but as we now demonstrate, also on the functioning of their own OT system. The OT system underpins the motivation to bond with others (Gordon et al, 2011), gives saliency to social cues (Bartz et al, 2011), and reduces the stress involved in social initiation (Neumann, 2008). At this initial stage of friendship formation, the unique elements of child-friend reciprocity may provide new opportunities for intervention. 
Like the findings for monkeys, introducing healthy peers to children growing in contextual risk or those deprived of adequate mothering by using structured and well-planned social opportunities may carry marked effects on children's social capacities during this critical transition from infancy to childhood.

Limitations of the study should be remembered in the interpretation of the findings. First, the correlations found here are mild-to-medium and many other biological and social factors have a role in shaping children's OT and reciprocal friendships. The sample included middle-class two-parent families who live in relative stability, and this may have played a role in the stability found here in parental and child OT. Under more chaotic conditions the cross-generation transfer of OT and parenting may have shown lower consistency. Additionally, the sample size is relatively small for genetic analyses and the findings should be replicated in larger samples. We chose two SNPs on the OXTR that have been linked with the risk for autism in the Israeli population, but did not include the OXTRrs53576, which has been associated with attachment processes and should be tested in relation to the transfer of attachment. Finally, because the links between OXTR and social risk differs by ethnicity, the findings should be replicated in other ethnic groups.

Future research should profitably examine the crossgeneration transfer in cases involving marked disturbances to maternal-infant bonding, such as those related to traumatic childbirth, prematurity, high contextual risk, or maternal inability to bond due to postpartum depression. Prospective longitudinal designs that can follow infants to adulthood and assess the roles of genes, hormones, and early caregiving for the child's future capacity to form friendships, fall in love, and provide adequate parenting are critical for a fuller understanding of human attachment. Although, very difficult to conduct, such studies can nevertheless provide invaluable information on early critical periods in the development of affiliative bonds, the potential of friendships for repairing disruptions in early parent-infant bonding, and the effects of reciprocityfocused interventions in mitigating the negative effects of diminished caregiving on the infant's lifetime capacity to form and maintain close attachments.

\section{ACKNOWLEDGEMENTS}

We thank Dr. Orna Zagoory-Sharon for hormonal analysis and the families participating in the study. Research was supported by the NARSAD independent investigator award, the Israel Science Foundation (no.1318/08), the Katz family foundation, and the Irving B. Harris Foundation.

\section{DISCLOSURE}

The authors declare no conflict of interest.

\section{REFERENCES}

Bakermans-Kranenburg MJ, van Ijzendoorn MH (2008). Oxytocin receptor (OXTR) and serotonin transporter (5-HTT) genes associated with observed parenting. Soc Cogn Affect Neurosci 3: $128-134$.
Bartz JA, Zaki J, Bolger N, Ochsner KN (2011). Social effects of oxytocin in humans: context and person matter. Trends Cogn Sci 15: 301-309.

Baumeister RF, Leary MR (1995). The need to belong-desire for interpersonal attachments as a fundamental human-motivation. Psychol Bull 117: 497-529.

Belsky J (1981). Early human-experience-a family perspective. Dev Psychol 17: 3-23.

Belsky J, Jonassaint C, Pluess M, Stanton M, Brummett B, Williams R (2009). Vulnerability genes or plasticity genes? Mol Psychiatry 14: 746-754.

Bowlby J (1958). The nature of the child's tie to his mother. Int $J$ Psychoanalysis 39: 350-373.

Bowlby J (1969). Attachment and loss. Basic Books: New York.

Brunetti E, Malavasi F (2012). CD38 and behavior: moving from correlation to causality? Biol Psychiatry 72: 168-170.

Burri A, Heinrichs M, Schedlowski M, Kruger TH (2008). The acute effects of intranasal oxytocin dministration on endocrine and sexual function in males. Psychoneuroendocrinology 33: 591-600.

Carter CS (2007). Sex differences in oxytocin and vasopressin: implications for autism spectrum disorders? Behav Brain Res 176: $170-186$.

Carter CS, Bales KL, Porges SW (2005). Neuropeptides influence expression of and capacity to form social bonds. Behav Brain Sci 28: 353-35.

Champagne FA (2008). Epigenetic mechanisms and the transgenerational effects of maternal care. Front Neuroendocrinol 29: 386-397.

Cohen S (2004). Social relationships and health. Am Psychol 59: 676-684.

Costa B, Pini S, Gabelloni P, Abelli M, Lari L, Cardini A et al (2009). Oxytocin receptor polymorphisms and adult attachment style in patients with depression. Psychoneuroendocrinol 34: 1506-1514.

Denenberg VH, Rosenberg KM (1967). Nongenetic transmission of information. Nature 216: 549-550.

Ditzen B, Schaer M, Gabriel B, Bodenmann G, Ehlert U, Heinrichs M (2009). Intranasal oxytocin increases positive communication and reduces cortisol levels during couple conflict. Biol Psychiatry 65: 728-731.

Eckerman CO, Davies CC, Didow SM (1989). Toddlers' emerging ways of acheiving social coordinations with a peer. Child Dev 60: 440-453.

Ellison CG (1990). Family ties, friendships, and subjective wellbeing among black-americans. J Marriage Fam 52: 298-310.

Fagot BI (1997). Attachment, parenting, and peer interactions of toddler children. Dev Psychol 33: 489-499.

Feldman R (1998): Coding Interactive Behavior Manual. Bar Ilan University, Ramat Gan, Israel. Feldman, R. 2007. On the origins of background emotions; from affect synchrony to symbolic expression. Emotion 7: 601-611.

Feldman R (2007). On the origins of background emotions; From affect synchrony to symbolic expression. Emotion 7: 601-611.

Feldman R (2010). The relational basis of adolescent adjustment: trajectories of mother-child interactive behaviors from infancy to adolescence shape adolescents' adaptation. Attach Hum Dev 12: $173-192$.

Feldman R (2012a). Oxytocin and social affiliation in humans. Horm Behav 61: 380-391.

Feldman R (2012b). Parenting behavior as the environment where children grow. In: Mayes LCLewis M (Eds) The Cambridge Handbook of Environment in Human Development. Cambridge University Press: New York, pp 535-567.

Feldman R, Eidelman AI (2004). Parent-infant synchrony and the social-emotional development of triplets. Developmental Psychology 40: 1133-1147.

Feldman R, Eidelman AI (2007). Maternal postpartum behavior and the emergence of infant-mother and infant-father synchrony in preterm and full-term infants: the role of neonatal vagal tone. Dev Psychobiol 49: 290-302. 
Feldman R, Gordon I, Shneiderman I, Weisman O, ZagoorySharon O (2010). Natural variations in maternal and paternal care are associated with systematic changes in Oxytocin following parent-infant contact. Psychoneuroendocrinology 35: 1133-1141.

Feldman R, Gordon I, Zagoory-Sharon O (2011). Maternal and paternal plasma, salivary, and urinary oxytocin and parentinfant synchrony: considering stress and affiliation components of human bonding. Dev Sci 14: 752-761.

Feldman R, Masalha S (2010). Parent-child and triadic antecedents of children's social competence: cultural specificity, shared process. Dev Psychol 46: 455-467.

Feldman R, Weller A, Zagoory-Sharon O, Levine A (2007). Evidence for a neuroendocrinological foundation of human affiliation: plasma oxytocin levels across pregnancy and the postpartum period predict mother-infant bonding. Psychol Sci 18: $965-970$.

Feldman R, Zagoory-Sharon O, Weisman O, Schneiderman I, Gordon I, Maoz R et al (2012). Sensitive parenting is associated with plasma oxytocin and polymorphisms in the OXTR and CD38 genes. Biol Psychiatry 72: 175-181.

Furman DJ, Chen MC (2011). Gotlib ICH. Variant in oxytocin receptor gene is associated with amygdala volume. Psychoneuroendocrinol 36: 891-897.

Gayer-Anderson C, Morgan C (2012). Social networks, support and early psychosis: a systematic review. Epidemiol Psychiatr Sci (e-pub ahead of print 26 July 2012).

Gordon I, Martin C, Feldman R, Leckman JF (2011). Oxytocin and social motivation. Dev Cogn Neurosci 1: 471-493.

Gordon I, Zagoory-Sharon O, Leckman JF, Feldman R (2010). Oxytocin and the development of parenting in humans. Biol Psychiatry 68: 377-382.

Harlow HF, Suomi SJ (1971). Social recovery by isolation-reared monkeys. Proc Natl Acad Sci USA 68: 1534-1538.

Higashida H, Yokoyama S, Kikuchi M, Munesue T (2012). CD38 and its role in oxytocin secretion and social behavior. Horm Behav 61: 351-358.

Hofer MA (1995). Hidden regulators: Implications for a new understanding of attachment, separation, and loss In: Golberg SMuir RKerr J (Ed) (Attachment theory: Social, developmental, and clinical perspectives Analytic Press: Hillsdale, NJ, pp 203-230.

Howes C (1988). Peer interaction of young children. Society for Research in Child Development: Chicago, Ill.

Inoue H, Yamasue H, Tochigi M, Abe O, Liu X, Takei K et al (2010). Association between the oxytocin receptor gene and amygdalar volume in healthy adults. Biol Psychiatry 68: 1066-1072.

Jin D, Liu HX, Hirai H, Torashima T, Nagai T, Lopatina $\mathrm{O}$ et al (2007). CD38 is critical for social behaviour by regulating oxytocin secretion. Nature 446: 41-45.

Kappeler L, Meaney MJ (2010). Epigenetics and parental effects. BioEssays: news and reviews in molecular, cellular and developmental biology 32: 818-827.
Kim HS, Sherman DK, Sasaki JY, Xu J, Chu TQ, Ryu C et al (2010). Culture, distress, and oxytocin receptor polymorphism (OXTR) interact to influence emotional support seeking. Proc Natl Acad Sci USA 107: 15717-15721.

Rutter M (2007). Gene-environment interdependence. Developmental Science 10: 12-18.

Lerer E, Levi S, Israel S, Yaari M, Nemanov L, Mankuta D et al (2010). Low CD38 expression in lymphoblastoid cells and haplotypes are both associated with autism in a family-based study. Autism Res 3: 293-302.

Lerer E, Levi S, Salomon S, Darvasi A, Yirmiya N, Ebstein RP (2008). Association between the oxytocin receptor (OXTR) gene and autism: relationship to Vineland Adaptive Behavior Scales and cognition. Mol Psychiatry 13: 980-988.

Lorenz K (1950): So kam der Mensch auf den Hund. G. BorothaSchoeler, Wien,. Munesue T, Yokoyama S, Nakamura K, et al., 2010, Two genetic variants of CD38 in subjects with autism spectrum disorder and controls. Neurosci Res 67: 181-191.

Neumann ID (2008). Brain oxytocin: a key regulator of emotional and social behaviours in both females and males. J Neuroendocrinol 20: 858-865.

Ramani GB, Brownell CA, Campbell SB (2010). Positive and negative peer interaction in 3- and 4-year-olds in relation to regulation and dysregulation. J Genet Psychol 171: 218-250.

Riebold M, Mankuta D, Lerer E, Israel S, Zhong S, Nemanov L et al (2011). All-trans retinoic acid upregulates reduced CD38 transcription in lymphoblastoid cell lines from autism spectrum disorder. Mol Med 17: 799-806.

Ross HE, Young LJ (2009). Oxytocin and the neural mechanisms regulating social cognition and affiliative behavior. Front Neuroendocrinol 30: 534-547.

Rubin K, Ross H (1982): (Eds) Peer relationships and social skills in childhood. Springer: New York.

Schneiderman I, Zagoory-Sharon O, Leckman JF, Feldman R (2012). Oxytocin during the initial stages of romantic attachment: relations to couples' interactive reciprocity. Psychoneuroendocrinology 37: 1277-1285.

Seeman TE (1996). Social ties and health: the benefits of social integration. Ann Epidemiol 6: 442-451.

Strathearn L, Fonagy P, Amico J, Montague PR (2009). Adult attachment predicts maternal brain and oxytocin response to infant cues. Neuropsychopharmacology 34: 2655-2666.

Tinbergen N (1963). On aims and methods of ethology. Zeitschrift für Tierpsychologie 20: 410-433.

Weisman O, Zagoory-Sharon O, Feldman R (2012a). Oxytocin administration to parent enhances infant physiological and behavioral readiness for social engagement. Biol Psychiatry 72: 982-989.

Weisman O, Zagoory-Sharon O, Feldman R (2012b). Intranasal oxytocin administration is reflected in human saliva. Psychoneuroendocrionology 37: 1582-1586.

$\mathrm{Wu} \mathrm{N}, \mathrm{Li} \mathrm{Z}, \mathrm{Su}$ Y (2012). The association between oxytocin receptor gene polymorphism (OXTR) and trait empathy. J Affect Disord [Research Support, Non-U.S. Gov't] 138: 468-472. 